
\title{
25 Research Square \\ Can Southeast Asia continue to be a major rice bowl?
}

\section{Shen Yuan}

Huazhong Agricultural University

\section{Alexander Stuart}

International Rice Research Institute

Alice Laborte

International Rice Research Institute

Juan Rattalino Edreira

University of Nebraska-Lincoln

\section{Achim Dobermann}

International Fertilizer Association https://orcid.org/0000-0001-5728-5594

\section{Le Vu Ngoc Kien}

Institute of Policy and Strategy for Agriculture and Rural Development

\section{Lưu Thị Thúy}

Conventional Rice Research and Development Center

\section{Kritkamol Paothong}

Ayutthaya Rice Research Center

Prachya Traesang

Thailand Rice Science Institute

\section{Tint Khin Myo}

Mawlamyine University

\section{San Su Su}

International Rice Research Institute

\section{Marcelino Villafuerte II}

Philippine Atmospheric, Geophysical and Astronomical Services Administration

\section{Emma Quicho}

International Rice Research Institute

\section{Anny Pame}

International Rice Research Institute

\section{Rathmuny Then}

International Rice Research Institute

\section{Rica Flor}

International Rice Research Institute

\section{Neak Thon}


Rice Seed Development and Management Office, Department of Rice Crop

\section{Fahmuddin Agus}

Indonesian Center for Agricultural Land Resources Research and Development

\section{Nurwulan Agustiani}

Indonesian Center for Rice Research

\section{Nanyan Deng}

Huazhong Agricultural University

\section{Tao Li}

Applied GeoSolutions

Patricio Grassini ( $\sim$ pgrassini2@unl.edu )

pgrassini2@unl.edu https://orcid.org/0000-0002-7501-842X

\section{Article}

Keywords: export, food security, rice, self-sufficiency, Southeast Asia, yield gap, yield potential

Posted Date: November 1st, 2021

DOI: https://doi.org/10.21203/rs.3.rs-1011209/v1

License: (1) (1) This work is licensed under a Creative Commons Attribution 4.0 International License. Read Full License

Version of Record: A version of this preprint was published at Nature Food on March 24th, 2022. See the published version at https://doi.org/10.1038/s43016-022-00477-z. 


\section{Abstract}

Southeast Asia is a major rice-producing region, with high level of internal consumption and accounting for $40 \%$ of global rice exports. Limited land resources, climate change, and yield stagnation during recent years have once again raised concerns about the capacity of the region to meet the growing demand for rice and remain as a large net exporter. Here we use a modelling approach to map rice yield gaps and assess production potential and net exports by 2040 . We find that the average yield gap represents $48 \%$ of the yield potential estimate for the region. Exploitable yield gaps are relatively large in Cambodia, Myanmar, Philippines, and Thailand, but comparably smaller in Indonesia and Vietnam. Continuation of current yield trends will not allow Indonesia and Philippines to meet their domestic rice demand. In contrast, closing the exploitable yield gap would allow all countries to achieve rice self-sufficiency, with an aggregated annual rice surplus of 100 million tons available for export. Our study provides insights for increasing regional production on existing cropland by narrowing existing yield gaps.

\section{Introduction}

Southeast Asia has made remarkable progress in raising rice production over the past 50 years, mainly by increasing cropping intensity (that is, the number of crops grown on the same piece of land during a 12month period) and average yield ${ }^{1,2}$. As a result, the rice systems located in the river basins and deltas of this region now produce a large and stable surplus of rice that not only meets the regional demand, but also makes a substantial contribution to global food supply ${ }^{1,3,4}$. As a whole, the region accounts for $26 \%$ and $40 \%$ of global rice production and exports ${ }^{3}$, respectively, being a major rice supplier for other regions of the world such as Africa and the Middle East ${ }^{5}$. Given the projected $30 \%$ increase in global rice demand by 2050 , the continuing rise in rice trade, and the limited room available for other main rice-producing countries (e.g., China and India) to generate a rice surplus $2,6,7$, Southeast Asia will continue to play a critical role in ensuring global rice supply ${ }^{8}$.

The new millennium has brought a number of challenges to rice systems in Southeast Asia. First, despite global equilibrium models on food supply and demand previously predicting an abrupt decline in rice demand per capita $^{9}$, we now know that this parameter will remain relatively stable for most countries ${ }^{7,10}$. Hence, by 2050 , rice demand in Southeast Asia will increase by $c a .18 \%$ simply due to population growth ${ }^{3,7,10}$. Second, the two most populous countries in the region (Indonesia and Philippines), totaling nearly 380 million people, depend on rice imports to meet their domestic demand. Third, after few decades of steady increase in average rice yield, there is now evidence of yield stagnation in four of the six major rice-producing countries in Southeast Asia region (Indonesia, Myanmar, Thailand, and Vietnam) (Fig. 1A). Finally, rice harvested area has remained stable or even declined slightly in some countries recently (Fig. 1B), and is under growing threat of conversion for residential and industrial uses ${ }^{11}$. Meanwhile, irrigated rice area expansion is unlikely to occur due to lack of investments in irrigation infrastructure, physical and economic water scarcity, and environmental concerns ${ }^{12}$. Additionally, there is limited scope for further increasing cropping intensity, considering that two and up to three rice crops are 
now being grown in most of the rice systems in the region ${ }^{13}$ (Supplementary Fig. 1). Although it has been demonstrated that rice yields can be maintained in such intensive monoculture systems, it has also proven to be very difficult to raise them further, even with the best available varieties and technologies ${ }^{14}$.

Over the past decades, through renewed efforts, countries in Southeast Asia were able to increase rice yields and the region as a whole has continued to produce a large amount of rice that exceeded regional demand, allowing a rice surplus to be exported to other countries ${ }^{4}$. At question is whether the region will be able to retain its title as a major global rice supplier in the context of increasing global and regional rice demand, yield stagnation, and limited room for cropland expansion. Here we follow a data-intensive approach to estimate yield gaps (the difference between yield potential and average farmer yield, see Methods) across the major rice-producing countries in the region to determine whether there is still sufficient potential for increasing production on existing land and provide insight on whether the region can remain as a major global rice supplier or not.

\section{Results}

Current yield gaps. We estimate yield gaps based on the simulated yield potential (irrigated crops) or water-limited yield potential (rainfed crops) across the six major rice-producing countries in Southeast Asia (Cambodia, Indonesia, Myanmar, Philippines, Thailand, and Vietnam), which together account for $97 \%$ of total rice production in the region ${ }^{3}$. Our assessment includes both irrigated and rainfed lowland rice systems, which roughly account for $98 \%$ of total rice production in Southeast Asia ${ }^{13,15}$, while deepwater and upland rice were not included. For irrigated rice, our definition of yield potential assumes no water and nutrient limitations and absence of weeds, pests, and diseases. The same definition applies to rainfed rice, except for inclusion of water limitation as a factor influencing the yield potential. At a regional level, yield potential averaged $8.9 \mathrm{Mg} \mathrm{ha}^{-1} \mathrm{crop}^{-1}$, ranging from 5.5 to $10.2 \mathrm{Mg} \mathrm{ha}^{-1} \mathrm{crop}^{-1}$ across the 11 country-water regimes combinations included in our analysis (Fig. 2). Variations in yield potential portray differences in water regime and climate, with highest values observed in irrigated systems or favorable environments for rainfed lowland rice production such as Indonesia and Philippines. In contrast, yield potential is the lowest for less productive but high value aromatic (Jasmine) rice varieties grown in water-limited environments in northeastern Thailand. The average annual yield potential in Southeast Asia is much higher in irrigated versus rainfed rice cropping systems because of higher seasonal yield potential in irrigated versus rainfed crop and because irrigation allows production of two and up to three rice crop cycles within the same year while most rainfed environments only allows cultivation of a single rice crop (Fig. 2; Supplementary Fig. 1). Yield potential is also influenced by difference in weather between crop seasons, with yield potential being ca. 10\% higher during the dry season compared with the wet season due to higher solar radiation ${ }^{13}$ (Supplementary Fig. 2).

At regional level, the average yield gap represents $48 \%$ of the potential (Fig. 2). This value represents the average across countries, water regimes, crop sequences, and soil types, after weighting by their relative share of total rice area. However, average values hide substantial differences in yield gaps among water 
regimes and countries. For example, average yield gap is $42 \%$ and $55 \%$ for irrigated and rainfed rice, respectively. While the previous analysis focuses on the average yield gap, the cropping intensity is also important to determine the available room for increasing annual rice production. For example, despite irrigated rice having a smaller yield gap than rainfed rice, its annual yield gap is larger due to higher cropping intensity (7.5 versus $5.2 \mathrm{Mg} \mathrm{ha}^{-1}$ year $^{-1}$ ) (Fig. 2). Regarding differences among countries, the yield gaps for irrigated rice are smaller in Indonesia and Vietnam (37-39\%) than in Cambodia, Myanmar, Philippines, and Thailand (51-60\%). In the case of rainfed rice, Indonesia exhibits a relatively smaller yield gap (49\%) compared with Cambodia, Myanmar, Philippines, and Thailand (54-66\%).

Our analysis also identifies regions at sub-national level with largest opportunities for increasing rice yield and production. For example, the yield gap is larger in the Red River delta compared with that of the Mekong delta in Vietnam (46 versus 39\%). In some cases, the magnitude of the yield gap is related to the previous history of intensification of rice production in the country. For example, in the case of Indonesia and Philippines, yield gaps are smaller in typical Green Revolution areas such as Java and Central Luzon, respectively, compared with other comparably newer rice-producing regions within these countries (Fig. 3). Our analysis also helps identify differences in the magnitude of the yield gap between cropping seasons. For example, we find a 7-16\% larger yield gap for irrigated rice grown during the dry versus wet season in Indonesia and Philippines but this pattern is the opposite in the case of irrigated rice in Cambodia and Vietnam (Supplementary Fig. 2).

Prospects for rice self-sufficiency and rice surplus. The current average (2019-2020) rice self-sufficiency ratio (SSR) in the entire Southeast Asia region is 1.10, with an estimated surplus of 17 million tons (Mt) (Fig. 4). However, there are contrasting patterns among countries, with rice production largely exceeding domestic consumption in Thailand and Vietnam, while Indonesia and Philippines rely on rice imports (Fig. 4 and Supplementary Fig. 3 and Table 1). The latter two countries have struggled consistently to meet their rice demand from own production and, considering strong population growth and agro-climatic constraints $^{8,16}$, this situation is not likely to change easily. The degree to which Southeast Asia can remain as a net rice exporting region in the future will ultimately depend upon changes in average yields and harvested area. Given the limited room for cropland expansion and cropping intensity, as one can infer from recent trajectories in harvested area (Fig. 1), we focus here on investigating rice SSR and surplus for different scenarios of yield increase during the next 20 years assuming that net harvested area remains unchanged. We investigate three scenarios, including continuation of current yield trends (S1), half closure of current exploitable yield gap (S2), and full closure of the exploitable yield gap (S3) (Fig. 4). For the calculation of the exploitable yield gap, we assume that achieving $80 \%$ of the yield potential for irrigated crops and $70 \%$ of the water-limited yield potential for rainfed crops is a reasonable goal for farmers with access to markets, inputs, and extension services ${ }^{17-19}$. Such levels of productivity have also been consistently achieved in well-managed long-term experiments ${ }^{20}$.

Assuming current trends in rice yield remain unchanged until 2040 (S1), the Southeast Asia regional SSR will drop from the current 1.10 to 1.03 , almost eliminating the rice surplus at a regional level, and with Indonesia and Philippines failing to achieve rice self-sufficiency (Fig. 4). In contrast, if the exploitable 
yield gap is closed by half (S2), Southeast Asia would increase its regional SSR to 1.29 and almost triple the rice surplus up to $54 \mathrm{Mt}$, allowing Indonesia to become self-sufficient in rice and drastically reducing the need for rice imports in Philippines. Finally, a scenario in which the exploitable yield gap is completely closed by 2040 (S3) would allow the six countries to be rice self-sufficient, leading to a regional SSR of 1.55 and an aggregated rice surplus of $100 \mathrm{Mt}$, which is ca. six times larger than the current value. Achieving the level of yield gap closure set as targets for S2 and S3 would require annual rates of yield gain ranging from 36 to $67 \mathrm{~kg} \mathrm{ha}^{-1}$ and 79 to $135 \mathrm{~kg} \mathrm{ha}^{-1}$, respectively, with largest and smallest rates corresponding to Philippines and Thailand, respectively.

\section{Discussion}

Concerns about rice shortages are not new in Southeast Asia. In the early 1960s, the threat of a major famine was a major driver for the Green Revolution that resulted in increased cropping intensity, higher yields, lower rice prices, and greater food security throughout the region ${ }^{4,8}$. The initial step was a steep rise in the harvested rice area during the 1960s and 70s. This was followed by a period of fast yield increases in the decade from the mid-1970s to the mid-1980s due to nearly complete adoption of the first generations of the new rice varieties, associated increases in input use, and other technology improvements ${ }^{3,8,21}$. Interestingly, while this initial Green Revolution period ended in the mid-1980s in Indonesia and Philippines, it steadily continued in Vietnam for several decades ${ }^{22}$. In the 1990 s, concerns were raised about stagnating or even declining yields or total factor productivity in some of the most intensively rice areas of Southeast Asia, reiterating the urgent need for closing existing yield gaps ${ }^{23}$. The concerns about rice shortages are back now. Our analysis shows that the Southeast Asia region will not be able to produce a large rice surplus in the future with the most recent rates of annual rice yield gains. Failure to increase yield on existing cropland area will drastically reduce the rice exports to other regions and the capacity of many countries in the region to achieve or sustain rice self-sufficiency. It also means that many countries in the region would need to rely on regional trade to meet their domestic rice demand, which in itself is not necessarily a disadvantage if rice market liberalization takes place ${ }^{24}$. Hence, although achieving rice self-sufficiency at country level should not be taken as the ultimate goal, we note that reaching a reasonable level of SSR for key staple crops is desirable for countries with limited capacity to purchase and distribute large amount of food imports ${ }^{25}$. Furthermore, for practically all Southeast Asian countries, rice is of strategic importance in terms of food security, political stability, economy and export potential.

Governments from many countries in Southeast Asia have made explicit their desire to secure stable food prices, completely avoid rice imports in the future, and/or increase income from exports ${ }^{20,26}$. Our analysis shows that this is possible but only for a scenario where large and strategic investments in agricultural policies, innovation, and R\&D help accelerate rates of yield gains so that the exploitable yield gap is narrowed down substantially within the next 20 years. We believe that this is feasible considering that current yield gaps in Southeast Asia are comparably larger than those in other rice-producing countries such as China and USA ${ }^{27,28}$, especially in Cambodia, Myanmar, Philippines, and Thailand where current 
yield gaps are $50-70 \%$ of yield potential. Also, we note that the required rates of annual yield gain to narrow down the exploitable yield gap (S2 and S3 scenarios) are similar to historical yield gains observed over the past 30 years for other rice-producing countries, such as China, USA, and Uruguay 3,28,29, and even to those achieved in Southeast Asia in the past (Fig. 1 and Supplementary Table 2). The importance of maintaining the capacity of Southeast Asia to produce a large rice surplus goes beyond the region, as it can help reduce global price volatility and provide a stable and affordable rice supply to many countries in Sub-Saharan Africa and the Middle East ${ }^{8,21}$.

Our estimated yield gaps are of similar magnitude to those reported by previous studies for specific countries or rice seasons in Southeast $\mathrm{Asia}^{30-32}$. However, the regional extent of our study, together with the level of detail in relation to spatial and temporal variation in yield gaps and specificity in terms of cropping systems is unique, providing a basis for prioritizing agricultural R\&D and investments at regional, national, and sub-national levels ${ }^{33}$. These regional and seasonal differences in yield gaps would not have been detected using top-down modeling approaches that ignore the complexity and diversity of rice systems in Southeast Asia ${ }^{34}$. For example, while rainfed rice exhibits a larger yield gap, our study shows that closure of yield gaps in irrigated rice can lead to a larger impact on annual rice production due to higher cropping intensity. We note that our study did not include the negative potential impact of climate change on yield, which may reduce our estimates of rice production and add further pressure on yield gap closure ${ }^{35}$. Climate change impacts on rice yields will require adaptation strategies to sustain yield growth against a backdrop of rising temperatures and sea water levels, which particularly affect the Mega Deltas of Southeast Asia ${ }^{36}$. However, climate change operates over longer time scales and its impact on rice yield trends are typically over-written by agro-ecological, seasonal, and management effects $^{37}$. It is also reasonable to assume that numerous adaptation measures will allow farmers adapting their cropping systems and practices to a changing climate. Therefore, we believe it is reasonable to ignore the effect of climate change on rice production for our assessment considering our relatively short timeframe (20 years) and the challenges in modeling changes in yield and crop management as determined by climate change ${ }^{17,38}$. Similarly, our study does not consider the improvement in genetic rice yield potential over time, including adaptation to rising temperatures or more frequent droughts or floods. However, we are cautious about the associated timeline and potential impact. For example, we note that the yield potential of inbred rice varieties has not changed substantially over the past 65 years ${ }^{39,40}$. Similarly, efforts to achieve a step-change in rice yield potential by incorporating $\mathrm{C}_{4}$ photosynthetic pathway will not lead to any commercially available variety in the near future ${ }^{41}$. In the case of hybrid rice, which can produce $15-20 \%$ higher yield than inbred rice ${ }^{42}$, we note that its adoption has been limited in Southeast Asia (less than $5 \%$ of regional harvested area) due to high seed price and trade-offs with grain quality ${ }^{43,44}$. Even when yield potential can be increased, increasing production would still require continuous agronomic improvements to exploit the resulting larger yield gap. Finally, we recognize that, besides yield gap closure, there may be others opportunities to increase the total milled rice output, for example, by reducing harvest and post-harvest losses, and improving milling rates ${ }^{45}$. 
In terms of the required interventions that are needed to close the current yield gap, improving crop management practices, especially nutrient and water management, and control of biotic factors, are likely to play a central role $20,23,46,47$. Production risk is also important for prioritizing agricultural R\&D. This is particularly the case of rainfed lowland rice, which accounts for nearly one third of harvested rice area in Southeast Asia ${ }^{14}$, where uncertainty in rainfall (either too much or too little) makes farmers reluctant to adopt improved crop management technologies and use external inputs such as fertilizers and pesticides ${ }^{13,46}$. Use of pumps and crop insurance can help these farmers to deal with inherently higher risk of growing rice in rainfed lowland environments. Closing of these gaps requires not only fine-tuning of crop management but also the concerted effort of policymakers, researchers, and extension services to facilitate farmers' access to technologies, information, and markets. It is also important to recognize a number of challenges in achieving this next and greener 'Green Revolution' for rice in Southeast Asia. The first challenge is how to foster yield increases without substantial trade-offs in grain quality, which might limit rice acceptance in local and global markets, which is of critical importance for export countries such as Thailand and Vietnam ${ }^{8,21}$. Another challenge is how to increase yield while minimizing the negative environmental impact associated with intensive rice production ${ }^{36}$. We believe a number of lessons can be learned from the past. For example, we know now that knowledge-based site-specific nutrient management can help tailor nutrient management to each environment, helping increase yield and farmer profit while reducing nutrient losses ${ }^{23,48}$. Likewise, integrated pest management is a knowledge intensive but valuable approach, if applied correctly and holistically, to reduce yield losses to weeds, pests, and diseases while minimizing excessive use of pesticides and associated risks to the environment and people ${ }^{49}$. It can be argued that re-arrangement of crop sequence in terms of sowing and harvest windows, can also be explored as a way to increase productivity. We note, however, that farmers are often restricted in how they can allocate labor, time, and resources within their socio-economic context, which may limit re-configuration of current crop sequences ${ }^{50}$. Regardless the means to achieve this next and greener 'Green Revolution', we note that failure to do it will not only cause political instability, but also put additional pressure on land and water resources, thus risking further encroachment into natural ecosystems such as forests and wetlands $21,26,36$.

\section{Methods}

Site selection. The six major rice-producing countries in Southeast Asia were selected for our analysis, including Cambodia, Indonesia, Myanmar, Philippines, Thailand, and Vietnam. Altogether, these countries account for $97 \%$ of total harvested rice area and production in Southeast Asia ${ }^{3}$. Rice cropping systems are diverse across Southeast Asia, including different ecosystems (lowland and upland), water regimes (rainfed and irrigated), and cropping intensity (single, double, and triple) ${ }^{13}$. Here, we focused on irrigated rice and rainfed lowland rice production. We noted that only irrigated rice was considered for Vietnam as rainfed rice production was small. Similarly, we excluded rainfed upland rice from our analysis as it accounts for less than $5 \%$ of national rice production across our six selected rice-producing countries and 
its contribution to national rice production has declined steadily over time ${ }^{14,19}$. Hence, our analysis included a total of 11 country-water regimes combinations.

We followed the protocols established by the Global Yield Gap Atlas (www.yieldgap.org) to estimate yield potential and yield gaps ${ }^{51,52}$. Following these protocols, a number of representative sites were selected and site-specific data on weather, soil, and crop management and a well-validated crop simulation model (ORYZA v3) were used to estimate yield potential (irrigated rice) and water-limited yield potential (rainfed lowland rice) ${ }^{53}$. In relation to site selection, we first used the Spatial Production Allocation Model map (SPAM 2010; www.mapspam.info), together with expert opinion from local researchers, to identify the spatial distribution of the rice harvested area in each country separately for each of the 11 country-water regime combinations (see Supplementary Information Text Section 2 for details, Supplementary Fig. 4). Second, based on the current distribution of meteorological stations, we selected reference weather stations (RWS) for each country-water regime combination. In each country, climate zones (CZ) accounting for $>5 \%$ of total harvested rice area for each water regime were identified. Each CZ represents a specific combination of annual growing-degree days, water balance, and temperature seasonality ${ }^{52}$. Circular buffer zones with a 100-km radius were created around each RWS and clipped by the CZs where the RWS was located in each country. For each country-water regime combination, buffers were iteratively selected starting from the one with largest harvested rice area, avoiding the buffers that overlap with the selected buffers by $20 \%$. This process was repeated until the sum of rice coverage across selected buffers reached at least $50 \%$ of the national total harvested rice area for each water regime. In the case of Indonesia and rainfed rice in Thailand, we created eight and three additional buffers (also further referred to as RWS buffers), respectively, to cover rice area in Indonesia and important rainfed lowland riceproducing area in the northeastern Thailand that were not included due to the lack of meteorological stations. As a result, a total of 69 and 61 RWS buffers were selected for irrigated and rainfed lowland rice in the six selected rice-producing countries, respectively (see Supplementary Information Text Section 2 for details, Supplementary Table 3).

Weather and soil data source. Long-term measured daily weather data is required for robust estimation of yield potential and its variability. Simulation of yield potential for irrigated rice requires solar radiation and maximum and minimum temperature, and, in the case of rainfed rice, precipitation and relative humidity are also needed. Daily measured data from the most recent 10 years were available for the selected RWS buffers in our study, except for the additional 11 buffers created for Thailand and Indonesia (see Supplementary Information Text Section 3 for details, Supplementary Table 4). For these 11 sites, we used gridded data from the NASA-POWER Agro-climatic database ${ }^{54}$. Following Van Wart et al. ${ }^{55}$ and Grassini et al. ${ }^{35}$, both measured and gridded weather data used in this study were subjected to quality control measures to fill in missing data and/or identify and correct erroneous values.

For irrigated rice, soil properties were not specified as yield potential is not influenced by soil properties, i.e. water and nutrient supply are not considered limiting for plant growth ${ }^{53,56}$. In the case of rainfed rice, simulation of water-limited yield potential required specification of soil properties related with the soil 
water balance, including water holding capacity, soil depth, and water table depth ${ }^{53}$. In our study, default soil parameters from PADDYIN file for a clay soil set in ORYZA v3 were applied to simulate water-limited yield potential for rainfed lowland rice in Indonesia, Myanmar, and Philippines. However, soil parameters were modified for our simulations of water-limited yield potential for rainfed lowland rice in northern and northeastern Thailand in order to portray the coarse-texture soils that prevail in these regions ${ }^{57-59}$. In the case of Cambodia, separate simulations of water-limited yield potential for rainfed lowland rice were performed for clay and coarse-texture soils, as these two soil types are important in the rice growing area in Cambodia ${ }^{60}$.

Crop management and actual yield. The dominant rice cropping systems were identified in the major riceproducing regions in each country. A rice cropping system is defined as a unique combination of ecosystem (lowland, upland), water regime (irrigated, rainfed), and rice cropping intensity (single, double, triple) as defined by the number, type, and temporal cycle of crops planted on the same piece of land over a 12-month period. As such, a total of 182 RWS buffer-cropping system combinations were identified in our study. For simulating yield potential, information on crop management including water regime, crop establishment method, sowing or transplanting window, maturity window, probability of drought, and rice variety name were collected for each rice cycle in each cropping system via structured questionnaires completed by local agronomists and extension personnel in each country (see Supplementary Information Text Section $\mathbf{4}$ for details). Selected crop calendars for typical rice cropping systems in each country are shown in Supplementary Fig. 1. Data on average farmer yields and rice harvested area were retrieved from official statistics at regional/state level for the most recent four years for Myanmar, at regency administration level for the most recent six years for Indonesia, and at provincial level for at least the most recent five years for the other four countries (see Supplementary Information Text Section $\mathbf{4}$ for details, Supplementary Table 5). Data on farmer yield were adjusted to a standard moisture content of $140 \mathrm{~g} \mathrm{H}_{2} \mathrm{O} \mathrm{kg}^{-1}$ rice grain.

Yield potential simulation. Yield potential (irrigated rice) and water-limited yield potential (rainfed lowland rice) were simulated using the crop growth and development model ORYZA v3 and data on actual crop management, measured daily weather, soil characteristics, and characteristics of representative rice varieties ${ }^{53}$. This model has been well validated in field experiments established in a wide range of environments and extensively used to simulate yield potential in various rice cropping systems worldwide ${ }^{61-64}$. To the extent that it was possible, we attempted to simulate modern rice varieties with broad adaptability that represent varieties widely grown in each of the six countries as determined based on expert opinion and national reports ${ }^{61,65-67}$. These varieties included Inpari 32 (Indonesia), 0M1490 (Vietnam and Cambodia), PSBRc80 (Philippines), and PSBRc10 (Myanmar). An exception was the fragrant Jasmine rice variety KDML105, which was used for simulation of water-limited yield potential in the rainfed lowland rice environment in northeastern Thailand as these types of varieties prevail in this region. Genetic coefficients of Inpari 32 were obtained from Agustiani et al. ${ }^{61}$ and crop parameters of OM1490, PSBRc80, and PSBRc10 were retrieved from Li et al. ${ }^{68}$. Briefly, the calibration and validation of the crop model in these previous studies was conducted with two independent datasets using measured 
data collected from well-managed field experiments. Genetic parameters were derived through iterating calibration and validation processes with initial values of crop parameters obtained from a wellcharacterized variety, IR72. Unfortunately, experimental data from well-managed crops were not available to calibrate model parameters for fragrant rice varieties. Hence, parameters of KDML105 were derived by using the crop parameters from OM1490 as initial value and subsequent addition of photoperiod sensitivity and lower partitioning to grain so that the simulated harvest index was around 0.40 . These adjustments in model parameters for fragrant rice were based on previously published studies for fragrant rice in northeastern Thailand and elsewhere ${ }^{32,58,69,70}$.

We simulated the yield potential (or water-limited yield potential in the case of rainfed lowland rice) for each rice cycle within each dominant cropping system for each of the RWS buffers selected for the 11 country-water regime combinations. For irrigated rice, we assumed no water limitation, while simulation of rainfed lowland rice considered precipitation, vapor pressure, and soil properties influencing the soil water balance, including soil texture and groundwater depth. For rainfed lowland rice, there is high uncertainty in relation with groundwater depth across sites, seasons, and landscapes, and its influence on rice yields ${ }^{71}$. Given the range of possible scenarios and associated uncertainties, we simulated waterlimited yield potential for rainfed lowland rice for different scenarios of groundwater depth during the entire crop cycle (shallow, medium, and deep). These three scenarios basically portray no water limitation (shallow), moderate-drought (medium), and drought-prone (deep) environments (see Supplementary Information Text Section $\mathbf{5}$ for details).

Yield gap estimation. For each rice cycle, the yield gap was calculated as the difference between yield potential (irrigated rice) or water-limited yield potential (rainfed lowland rice) and average farmer yield ${ }^{18}$. Average yield gap for each RWS was estimated by weighting yield potential and average yield based on the fraction of rice harvested area within each buffer accounted for by each cropping sequence-crop cycle combination. The annual yield gap was calculated based on the average rice cropping intensity in each RWS. In all cases, the yield gap was estimated separately for each country-water regime combination.

Current and future rice demand. Current (2019-2020) annual domestic rice demand was set as a baseline in our study. Current national rice demand in each of the six selected major rice-producing countries was estimated as the average annual national rice production, imports, exports, and stock change during 2019-202072 (Supplementary Table 6). Future (2040) rice demand for each country was estimated by multiplying the projected population derived from the medium fertility variant (http://population.un.org/wpp) by the per-capita rice demand by year 2040. The latter was estimated based on the relative change in average per-capita rice demand, between the baseline (2019-2020) and year 2040, derived for each country from the outputs of three econometric food supply-demand models: the International Rice Research Institute Global Rice Model (IGRM) ${ }^{73}$, the International Model for Policy Analysis of Agricultural Commodities and Trade (IMPACT) model ${ }^{10}$, and the Rice Economy Climate Change (RECC) model ${ }^{74}$ (Supplementary Table 6). Projected total rice demand by year 2040 is expected to be higher than the current (2019-2020) demand for all countries, except for Thailand and Vietnam 
where it will remain relatively similar. In this study, we also analyzed total rice demand and production at regional level by considering all 11 countries in Southeast Asia, that is, the six selected major riceproducing countries included in this study plus other five countries: Brunei, Laos, Malaysia, Singapore, and Timor-Leste ${ }^{75}$. To do this, current rice demand in the whole Southeast Asia was estimated as the average of annual regional total rice production, import, export, and stock variation (average of 20192020) 72 . We noted that the five countries not included in our analysis (Brunei, Laos, Malaysia, Singapore, and Timor-Leste) are net rice importers and their aggregated annual rice demand represents $5 \%$ of that calculated for the six countries selected for our study ${ }^{72}$. Hence, future (2040) total rice demand in Southeast Asia was estimated by multiplying the projected rice demand from the six countries by 1.05 . In our study, all rice yield, production, per-capita rice demand, and total rice demand were reported as paddy rice at a standard moisture content of $140 \mathrm{~g} \mathrm{H}_{2} \mathrm{O} \mathrm{kg}^{-1}$ rice grain. We noted that per-capita rice demand was converted to paddy rice by dividing originally reported milled rice from the USDA databases and the three models by rice milling rate of each major rice-producing country ${ }^{10,72-74}$ (Supplementary Table 6).

Scenario assessment. We assessed rice production potential and its impact on rice surplus by comparing the projected rice production against rice demand by $2040^{17-19}$. We performed scenario analyses individually at the national level for the six selected major rice-producing countries and separately for the entire Southeast Asia. Similar to other studies assessing food supply-demand scenarios ${ }^{76,77}$, we used 2040 as the target year for our scenario assessment. A 20-year timespan would be long enough to facilitate long-term policies, investments, and technologies devoted to closing exploitable yield gap, and it is short enough to minimize long-term effects from climate change on crop yields and cropping systems. Similarly, we noted that population growth rates start to decline for the majority of the countries in Southeast Asia around or after 2040 (http://population.un.org/wpp).

Reaching $80 \%$ of the yield potential (irrigated crops) or $70 \%$ of the water-limited yield potential (rainfed crops) is a reasonable yield goal for farmers with good access to markets, inputs, and extension services, as evidenced by rainfed wheat in Germany and France, rainfed maize in USA, and irrigated rice in Egypt and China ${ }^{18,78}$ (www.yieldgap.org). Hence, the exploitable yield gap was defined here as the difference between $80 \%$ of yield potential (irrigated) or $70 \%$ of water limited yield potential (rainfed) and current average farmer yield. For our scenario assessment, we considered three scenarios of yield-gap closure. The first scenario was business-as-usual (S1), that is, continuation of current yield trends based on most recent rates of yield gains as derived from our analysis (Fig. 1 and Supplementary Table 2). The second scenario (S2) assumed that $50 \%$ closure of the existing exploitable yield gap can be achieved between now and 2040. Finally, the third scenario (S3) assumed a full closure of the exploitable yield gap by 2040 . We assumed that the current harvested rice area remained unchanged for all three scenarios, which was reasonable considering the flat trajectories in harvested area over past decades. Indeed, our assumption can be considered optimistic considering current pressure on converting lowland rice fields for urban and industrial uses, or diversifying into other crops. We also assumed no change in upland rice production, which currently accounts for less than $5 \%$ of national production across the six countries, although its area may decline further over time. We also assumed no change in the fraction of irrigated rice area, 
given lack of investments for irrigation schemes, physical and economic water scarcity, and

environmental concerns ${ }^{12}$. At a regional level of Southeast Asia, total rice production was estimated as the sum of projected rice production from the six selected rice-producing countries and that from the other five countries in each of the three scenarios. We assumed that rice production in the other five countries remained unchanged (in relative terms), which totaled an annual average of $5.6 \mathrm{Mt}$ from 2019 to 2020 , representing $3 \%$ of rice production in the six selected countries ${ }^{72}$. We noted that for the current baseline and for each of the three scenarios by 2040, we calculated the aggregated rice production, rice surplus, and the self-sufficiency ratio (SSR). Rice surplus and SSR were estimated as the difference and ratio between annual rice production and annual rice demand, respectively ${ }^{17}$ (Fig. 4).

\section{Declarations}

\section{Data availability}

Data on yield potential are available via the Global Yield Gap Atlas (www.yieldgap.org). All other data are available from the corresponding author upon reasonable request.

\section{Acknowledgements}

We would like to thank local agronomists and extension agents in each country for their help in data collection. We acknowledge the Swiss Agency for Development and Cooperation for financial support to conduct the CORIGAP survey (Grant 681 no. 7F-08412.02). We also thank the support from the National Natural Science Foundation of China (32101821, 32061143038), the China Postdoctoral Science Foundation (2020M682439), the Indonesian Agency for Agricultural Research and Development (IAARD), the Office of Global Engagement at the Institute of Agriculture and Natural Resources (IANR) at the University of Nebraska-Lincoln (UNL), and the UNL Daugherty Water for Food Global Institute.

\section{Author contributions}

S.Y., A.M.S., and P.G. conceived and designed the study. A.M.S., A.G.L., J.I.R.E., A.D., L.V.N.K., L.T.T., K.P., P.T., K.M.T., S.S.S., S.Y., M.Q.V.II, E.D.Q., R.T., R.J.F., N.T., A.R.P., N.D., N.A., F.A., and T.L. provided and compiled the data analyzed in this study. S.Y., J.I.R.E., N.D., and P.G. performed the spatial analysis, simulation, and data analysis. S.Y. and P.G. and wrote the paper, with contribution from other authors.

\section{Competing interests}

The authors declare no competing interests. 


\section{References}

1. OECD/FAO. OECD-FAO Agricultural Outlook 2017-2026 (OECD Publishing, Paris, France, 2017).

2. Frenken, K. Irrigation in Southern and Eastern Asia in figures AQUASTAT Survey-2011. FAO Water Reports (FAO, Rome, Italy, 2012).

3. FAO. FAOSTAT production data. (accessed 2 May 2021); .

4. Dawe, D., Jaffee, S. \& Santos, N. Rice in the shadow of skyscrapers: policy choices in a dynamic East and Southeast Asian setting (FAO, Rome, Italy, 2014).

5. Baldwin, K., Childs, N., Dyck, J. \& Hansen, J. Southeast Asia's rice surplus. Outlook No. RCS-121-01 (USDA, Washington DC, USA, 2012).

6. UN. World Population Prospects (Department of Economic and Social Affairs, Population Division, UN, New York, New York, USA, 2019). Online Edition. Rev. 1. 2019.

7. Rejesus, R. M., Mohanty, S. \& Balagtas, J. V. Forecasting global rice consumption (North Carolina State University, Raleigh, North Carolina, USA, 2012).

8. Clarete, R. L., Adriano, L. \& Esteban A. Rice trade and price volatility: Implications on ASEAN and global food security. Asian Development Bank Economics Working Paper Series (Asian Development Bank, Metro Manila, Philippines, 2013).

9. Pandey, S. et al. Rice in the global economy: strategic research and policy issues for food security (International Rice Research Institute, Los Baños, Philippines, 2010).

10. Robinson, S. et al. The International Model for Policy Analysis of Agricultural Commodities and Trade (IMPACT)-Model Description for Version 3, IFPRI Discussion Paper 1483 (International Food Policy Research Institute, Washington DC, USA, 2015).

11. d'Amour, C. B. et al. Future urban land expansion and implications for global croplands. Proc. Natl Acad. Sci. USA 114, 8939-8944 (2017).

12. de Fraiture, C. et al. Trends and transitions in Asian irrigation: What are the prospects for the future? IWMI-FAO workshop on Asian Irrigation (FAO-RAP, Bangkok, Thailand, 2009)

13. Global Rice Science Partnership. Rice almanac, 4th edition (International Rice Research Institute, Los Baños, Philippines, 2013).

14. Ladha, J. K. et al. Steady agronomic and genetic interventions are essential for sustaining productivity in intensive rice cropping. Proc. Natl Acad. Sci. USA 118, 00 e2110807118 (2021).

15. Mutert, E. \& Fairhurst, T. H. Developments in rice production in Southeast Asia. Better Crops Int. 15, 12-17 (2002).

16. Dawe, D. C., Piedad, M. \& Cheryll B. C. Why does the Philippines import rice?: meeting the challenge of trade liberalization (International Rice Research Institute, Los Baños, Philippines, 2006).

17. van Ittersum, M. K. et al. Can sub-Saharan Africa feed itself?. Proc. Natl Acad. Sci. USA 113, 1496414969 (2016). 
18. Lobell, D. B., Cassman, K. G. \& Field, C. B. Crop yield gaps: their importance, magnitudes, and causes. Annu. Rev. Environ. Resour. 34, 179 (2009).

19. Agus, F. et al. Yield gaps in intensive rice-maize cropping sequences in the humid tropics of Indonesia. Field Crops Res. 237, 12-22 (2019).

20. Roland, J. B., Teodoro, Q. C., Irish, L. B. P., Eufrocino, V. L. \& Il-Ryong, C. Yield of irrigated rice affected by asymptomatic disease in a long-term intensive monocropping experiment. Field Crops Res. 265, 108121 (2021).

21. Cosslett, T. L. \& Cosslett, P. D. Rice trade of the mainland Southeast Asian countries: Cambodia, Laos, Thailand, and Vietnam. Sustainable development of rice and water resources in Mainland Southeast Asia and Mekong River Basin (Springer, Singapore, Singapore, 2018).

22. Thi Ut, T. R. A. N. \& Kajisa, K. The impact of green revolution on rice production in Vietnam. Dev. Econ. 44, 167-189 (2006).

23. Dobermann, A., Witt, C. \& Dawe, D. Increasing productivity of intensive rice systems through sitespecific nutrient management (Science Publishers Inc. and International Rice Research Institute, Enfield NH, USA and Los Baños, Philippines, 2004).

24. Hoang, H. K. \& Meyers, W. H. Price stabilization and impacts of trade liberalization in the Southeast Asian rice market. Food Policy 57, 26-39 (2015).

25. Clapp, J. Food self-sufficiency: Making sense of it, and when it makes sense. Food Policy 66, 88-96 (2017).

26. Dawe, D. \& Timmer, C. P. Why stable food prices are a good thing: Lessons from stabilizing rice prices in Asia. Glob. Food Secur. 1, 127-133 (2012).

27. Deng, N. et al. Closing yield gaps for rice self-sufficiency in China. Nat. Commun. 10, 1-9 (2019).

28. Ray, D. K. et al. Recent patterns of crop yield growth and stagnation. Nat. Commun. 3, 1293 (2012).

29. Grassini, P., Eskridge, K. M. \& Cassman, K. G. Distinguishing between yield advances and yield plateaus in historical crop production trends. Nat. Commun. 4, 2918 (2013).

30. Stuart, A. M. et al. Yield gaps in rice-based farming systems: Insights from local studies and prospects for future analysis. Field Crops Res. 194, 43-56 (2016).

31. Affholder, F., Poeydebat, C., Corbeels, M., Scopel, E. \& Tittonell, P. The yield gap of major food crops in family agriculture in the tropics: Assessment and analysis through field surveys and modelling. Field Crops Res. 143, 106-118 (2013).

32. Boling, A. A., Bouman, B. A., Tuong, T. P., Konboon, Y. \& Harnpichitvitaya, D. Yield gap analysis and the effect of nitrogen and water on photoperiod-sensitive Jasmine rice in north-east Thailand. NJASWagen. J. Life Sci. 58, 11-19 (2011).

33. van Oort, P. A. et al. Can yield gap analysis be used to inform R\&D prioritisation?. Global Food Sec. 12, 109-118 (2017).

34. Edreira, J. R., Andrade, J., Cassman, K., van Ittersum, M., van Loon, M. \& Grassini, P. Spatial frameworks for robust estimation of yield gaps. Nat. Food https://doi.org/10.1038/s43016-021- 
00365-y (2021).

35. Grassini, P. et al. How good is good enough? Data requirements for reliable crop yield simulations and yield-gap analysis. Field Crops Res. 177, 49-63 (2015).

36. Redfern, S. K., Azzu, N. \& Binamira, J. S. Rice in Southeast Asia: facing risks and vulnerabilities to respond to climate change. Building Resilience for Adaptation to Climate Change in the Agriculture Sector (FAO, Rome, Italy, 2012).

37. Angulo, C., Becker, M. \& Wassmann, R. Yield gap analysis and assessment of climate-induced yield trends of irrigated rice in selected provinces of the Philippines. J. Agric. Rural Dev. Trop. Subtrop. 113, 61-68 (2012).

38. Pastor, A. V. et al. The global nexus of food-trade-water sustaining environmental flows by 2050 . Nat. Sustain. 2, 499-507 (2019).

39. Peng, S., Huang, J., Cassman, K. G., Laza, R. C., Visperas, R. M. \& Khush, G. S. The importance of maintenance breeding: a case study of the first miracle rice variety-IR8. Field Crops Res. 119, 342347 (2010).

40. Espe, M. B., Hill, J. E., Leinfelder-Miles, M., Espino, L. A., Mutters, R., Mackill, D., van Kessel, C. \& Linquist, B. A. Rice yield improvements through plant breeding are offset by inherent yield declines over time. Field Crops Res. 222, 59-65 (2018).

41. Ermakova, M., Danila, F. R, Furbank, R. T. \& von Caemmerer, S. On the road to $\mathrm{C}_{4}$ rice: advances and perspectives. Plant J. 101, 940-950 (2020).

42. Hari Prasad, A. S., Viraktamath, B. C. \& Mohapatra, T. Hybrid rice development in Asia: Assessment of limitations and potential (FAO Regional Office for Asia and the Pacific, Bangkok, Thailand, 2014).

43. FAORAP. Report on the regional expert consultation on hybrid rice development in Asia under FAOChina South-South cooperation: constraints and opportunities (FAO Regional Office for Asia and the Pacific, Bangkok, Thailand, 2016).

44. Xie, F. \& Peng, S. History and prospects of hybrid rice development outside of China. Sci. Bull. 35, 3858-3868 (2016).

45. Gummert, M. et al. Assessment of post-harvest losses and carbon footprint in intensive lowland rice production in Myanmar. Sci. Rep. 10, 1-13 (2020).

46. FAO. A regional rice strategy for sustainable food security in Asia and the Pacific (FAO Regional Office for Asia and the Pacific, Bangkok, Thailand, 2014).

47. Laborte, A. G. et al. Rice yields and yield gaps in Southeast Asia: past trends and future outlook. Eur. J. Agron. 36, 9-20 (2012).

48. Chivenge, P., Saito, K., Bunquin, M. A., Sharma, S., \& Dobermann, A. Co-benefits of nutrient management tailored to smallholder agriculture. Global Food Sec. 30, 100570 (2021).

49. Thomas, M. B. Ecological approaches and the development of "truly integrated" pest management. Proc. Natl Acad. Sci. USA 96, 5944-5951 (1999). 
50. Mortensen, D. A. \& Smith, R. G. Confronting barriers to cropping system diversification. Front. Sustain. Food Syst. 4, 564197 (2020).

51. van Bussel, L. G. et al. From field to atlas: upscaling of location-specific yield gap estimates. Field Crops Res. 177, 98-108 (2015).

52. van Wart, J. et al. Use of agro-climatic zones to upscale simulated crop yield potential. Field Crops Res. 143, 44-55 (2013).

53. Bouman, B. A. M. et al. ORYZA2000: Modeling Lowland Rice (International Rice Research Institute, Los Baños, Philippines, 2001).

54. NASA-POWER. POWER Data Methodology. (accessed 25 June 2020). http://power.larc.nasa.gov/docs.

55. Van Wart, J. et al. Creating long-term weather data from thin air for crop simulation modeling. Agr. Forest Meteorol. 209, 49-58 (2015).

56. van Ittersum, M. K. et al. Yield gap analysis with local to global relevance-a review. Field Crops Res. 143, 4-17 (2013).

57. Khunthasuvon, S. et al. Lowland rice improvement in northern and northeast Thailand: 1. Effects of fertiliser application and irrigation. Field Crops Res. 59, 99-108 (1998).

58. Naklang, K., Harnpichitvitaya, D., Amarante, S. T., Wade, L. J. \& Haefele, S. M. Internal efficiency, nutrient uptake, and the relation to field water resources in rainfed lowland rice of northeast Thailand. Plant Soil 286, 193-208 (2006).

59. Roy, R. N., Finck, A., Blair, G. J. \& Tandon, H. L. S. Plant nutrition for food security-A guide for integrated nutrient management (FAO, Rome, Italy, 2006).

60. White, P. F., Oberthür, T. \& Sovuthy, P. The soils used for rice production in Cambodia: a manual for their identification and management (International Rice Research Institute, Los Baños, Philippines, 1997).

61. Agustiani, N. et al. Simulating rice and maize yield potential in the humid tropical environment of Indonesia. Eur. J. Agron. 101, 10-19 (2018).

62. Espe, M. B. et al. Yield gap analysis of US rice production systems shows opportunities for improvement. Field Crops Res. 196, 276-283 (2016).

63. Yuan, S., Peng, S. \& Li, T. Evaluation and application of the ORYZA rice model under different crop managements with high-yielding rice cultivars in central China. Field Crops Res. 212, 115-125 (2017).

64. Li, T. et al. From ORYZA2000 to ORYZA (v3): An improved simulation model for rice in drought and nitrogen-deficient environments. Agr. Forest Meteorol. 237, 246-256 (2017).

65. Bouman, B. A. M. Developing a system of temperate and tropical aerobic rice in Asia (STAR), CPWF Project Report (CGIAR Challenge Program on Water and Food, Colombo, Sri Lanka, 2008).

66. Asian Development Bank. Regional: development and dissemination of climate-resilient rice varieties for water-short areas of South Asia and Southeast Asia (Asian Development Bank, Metro Manila, 
Philippines, 2016).

67. Nguyen, V. N. \& Tran, D. V. Rice in producing countries, FAO Rice Information (FAO, Rome, Italy, 2002).

68. Li, T. et al. Simulation of genotype performances across a larger number of environments for rice breeding using ORYZA2000. Field Crops Res. 149, 312-321 (2013).

69. Samson, B. K., Hasan, M. \& Wade, L. J. Penetration of hardpans by rice lines in the rainfed lowlands. Field Crops Res. 76, 175-188 (2002).

70. Haefele, S. M. et al. Factors affecting rice yield and fertilizer response in rainfed lowlands of northeast Thailand. Field Crops Res. 98, 39-51 (2006).

71. Boling, A. A. et al. The effect of toposequence position on soil properties, hydrology, and yield of rainfed lowland rice in Southeast Asia. Field Crops Res. 106, 22-33 (2008).

72. USDA. Foreign Agricultural Service. (accessed 2 May 2021); https://apps.fas.usda.gov/psdonline/app/index.html\#/app/advQuery.

73. Balié, J. \& Valera, H. G. Domestic and international impacts of the rice trade policy reform in the Philippines. Food Policy 92, 101876 (2020).

74. Koizumi, T., Gay, S. H. \& Furuhashi, G. Reviewing Indica and Japonica rice market developments (OECD Publishing, Paris, France, 2021).

75. United Nations Statistics Division (UNSD). Standard country or area codes for statistical use (M49) (UNSD, New York, USA, 1999).

76. Rega, C., Helming, J. \& Paracchini, M. L. Environmentalism and localism in agricultural and land-use policies can maintain food production while supporting biodiversity. Findings from simulations of contrasting scenarios in the EU. Land Use Policy 87, 103986 (2019).

77. Zhou, Y. \& Staatz, J. Projected demand and supply for various foods in West Africa: Implications for investments and food policy. Food Policy 61, 198-212 (2016).

78. Yuan, S. et al. A roadmap towards sustainable intensification for a larger global rice bowl. PREPRINT available at Research Square [https://doi.org/10.21203/rs.3.rs-401904/v1] (2021)

\section{Figures}



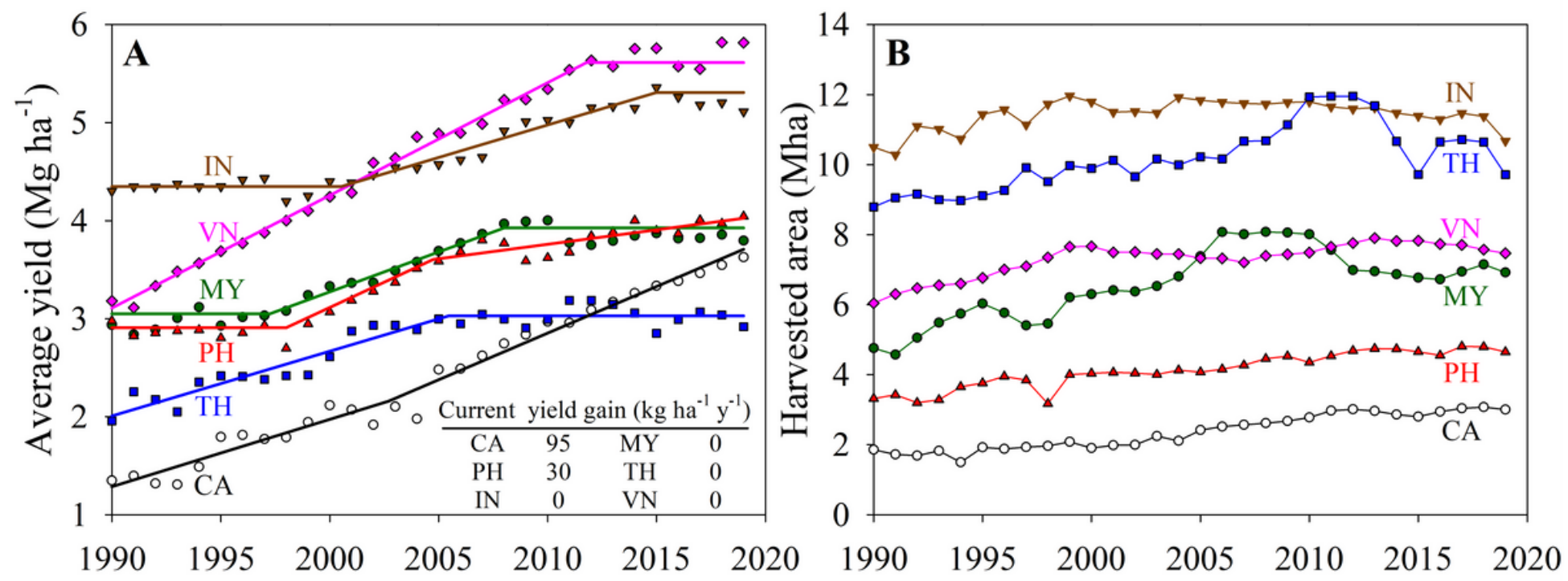

\section{Figure 1}

Trends in (A) average yield and (B) harvested area for rice in six major rice-producing countries in Southeast Asia: Cambodia (CA), Indonesia (IN), Myanmar (MY), Philippines (PH), Thailand (TH), and Vietnam (VN) during the past 30 years (1990-2019). Recent yield gains derived from the fitted models are shown in panel $(A)$; parameters of fitted models were all statistically significant $(p<0.05)$. Source: FAOSTAT3. 


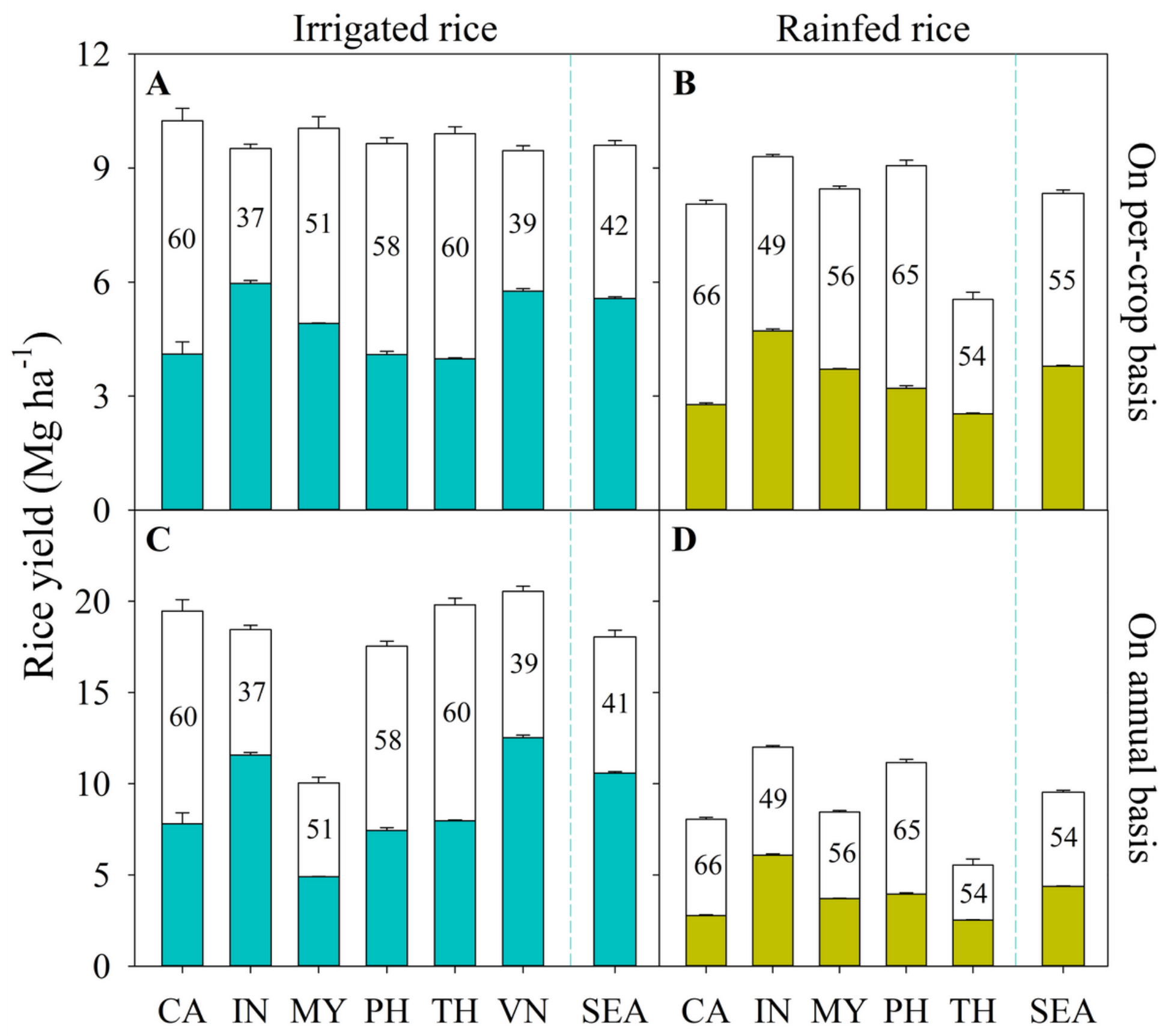

Figure 2

Average yield potential and water-limited yield potential for irrigated (left) and rainfed rice (right), respectively, for the six major rice-producing countries in Southeast Asia: Cambodia (CA), Indonesia (IN), Myanmar (MY), Philippines (PH), Thailand (TH), and Vietnam (VN) on per-crop (top) and annual basis (bottom). Solid and empty portions of bars indicate the average farmer yield and the yield gap, respectively. Vertical lines above solid and empty bars indicate standard errors. Values inside the empty portion of the bars indicate the average yield gap as percentage of yield potential (irrigated) or waterlimited yield potential (rainfed). Also shown are the regional area-weighted averages of Southeast Asia (SEA) for each water regime. 


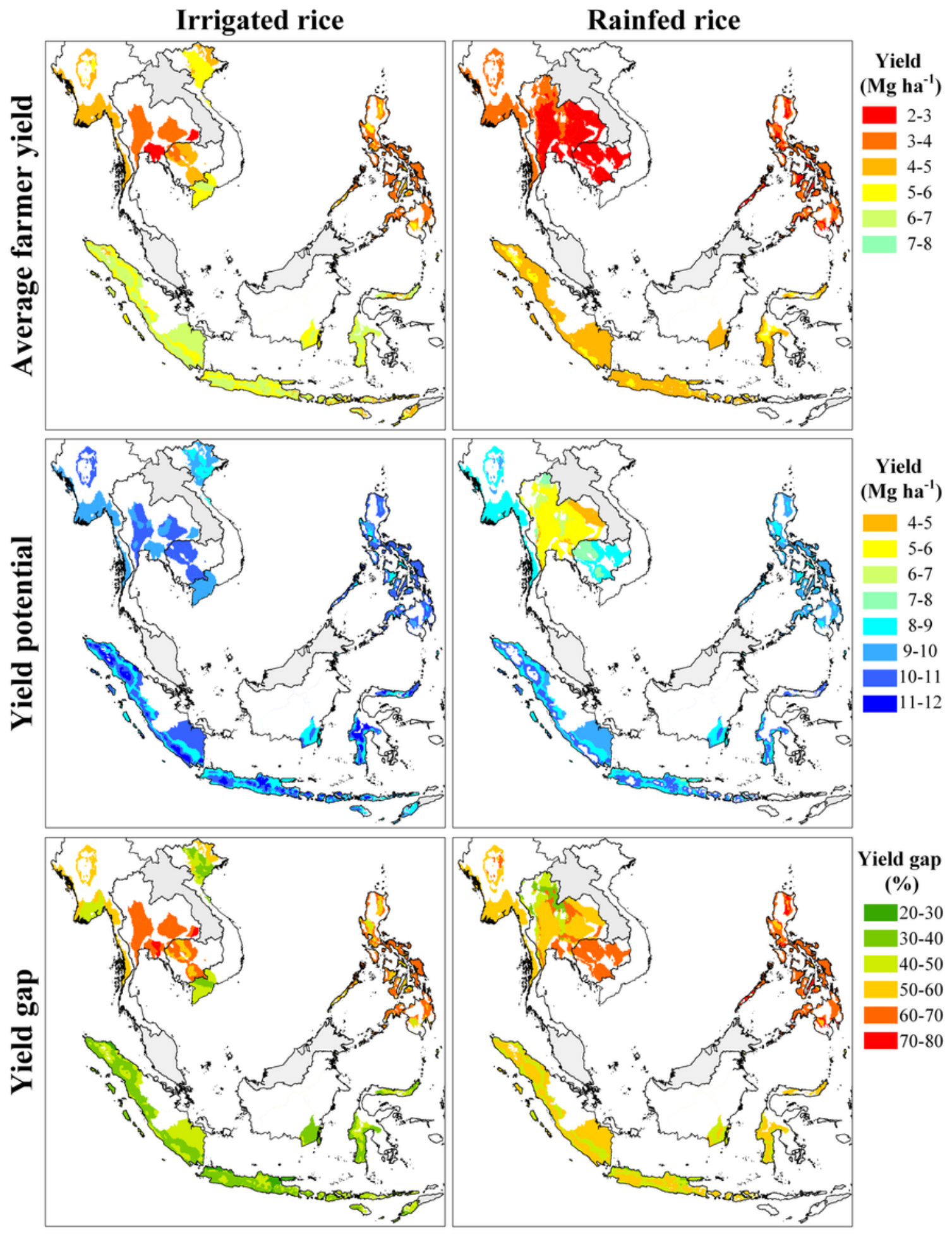

Figure 3

Average farmer yield, yield potential, and yield gap (as percentage of yield potential) for irrigated (left) and rainfed lowland rice (right) for the six major rice-producing countries in Southeast Asia at climate zone level. Other countries in Southeast Asia not included in our yield-gap analysis are shown in gray. 


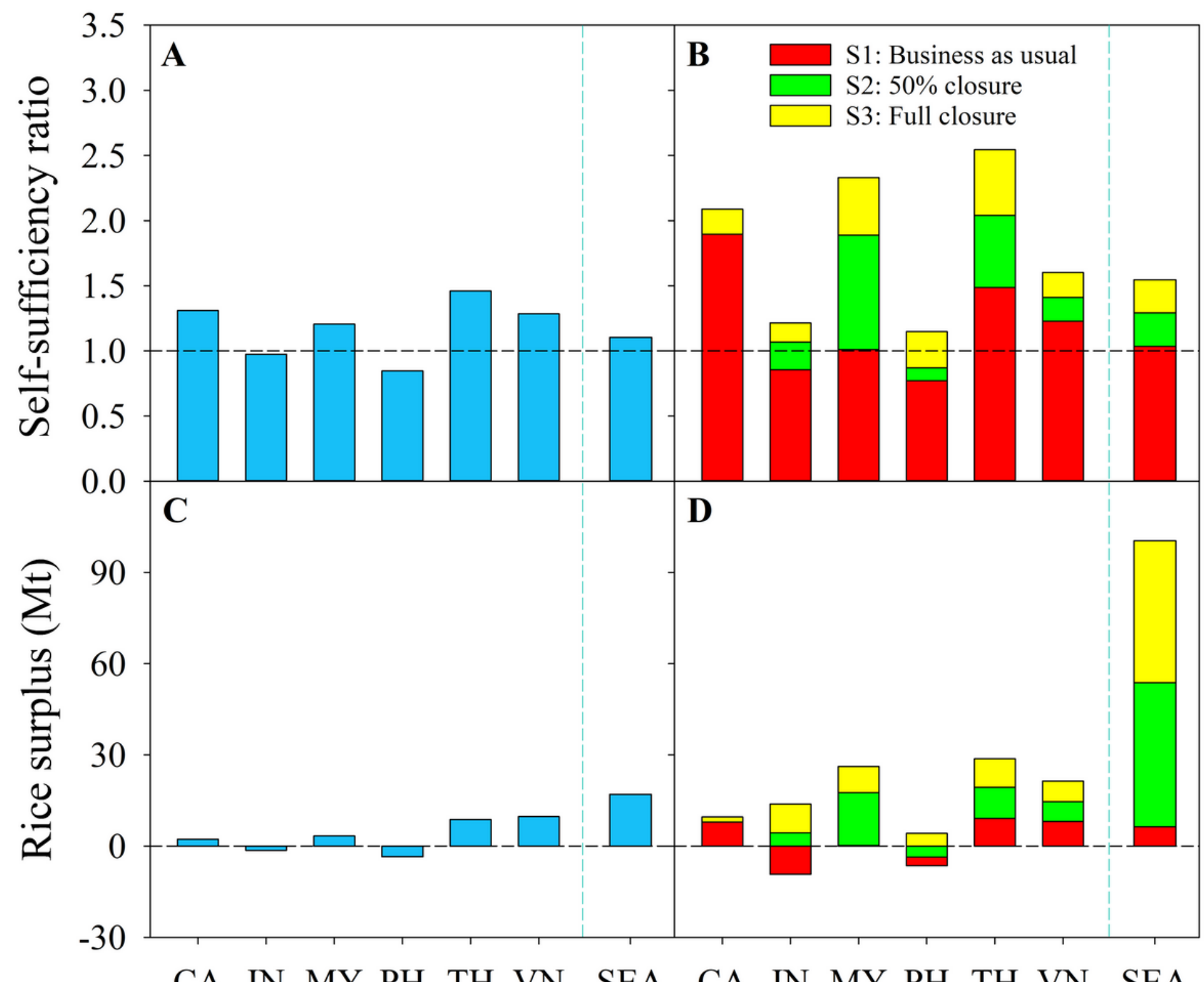

CA IN MY PH TH VN SEA CA IN MY PH TH VN SEA

Figure 4

Rice self-sufficiency ratio (top) and rice surplus (bottom) for the baseline (2019-2020, left) and three scenarios of yield increase towards year 2040 (right): continuation of historical yield trends (S1, red), half closure of exploitable yield gap (S2, green), and full closure of exploitable yield gap (S3, yellow). Separate values are shown for each country: Cambodia (CA), Indonesia (IN), Myanmar (MY), Philippines (PH), Thailand (TH), and Vietnam (VN). Also shown are the aggregated values for the entire Southeast Asia region (SEA, including six major rice-producing countries analyzed in this study plus the other five countries located in this region as a whole, see Methods). S2 is not shown for Cambodia as current yield gain is adequate to achieve half closure of the exploitable yield gap by 2040 .

\section{Supplementary Files}


This is a list of supplementary files associated with this preprint. Click to download.

- YuanetalSEAsiaSupportinginformation.docx 